\title{
INVESTIGATION THE INFLUENCE OF CHEMICAL COMPONENTS PENETRATING THE SURFACE OF SKD61 STEEL TO THE SURFACE MICROSTRUCTURE IN PMEDM PROCESS
}

\author{
VAN TAO LE ${ }^{*}$ \\ Advanced Technology Center, Le Quy Don Technical University, Hanoi, Vietnam
}

\begin{abstract}
The Electrical Discharge Machining (EDM) is a machining method that uses the heat to obtain during the discharge of a spark to remove materials from the workpiece. Thus, the process of sparking has changed surface properties. This work investigates the penetration of chemical components on the surface of SKD61 steel after being processed by the EDM method with the mixing of tungsten carbide powder (PMEDM) in to the dielectric fluid affecting the surface microstructure.

KEYWORDS: EDM, PMEDM, Surface Modification, Tungsten Carbide Powder \& Surface Microstructure
\end{abstract}

Received: Jun 08, 2020; Accepted: Jun 28, 2020; Published: Aug 12, 2020; Paper Id.: IJMPERDJUN2020751

\section{INTRODUCTION}

Electrical discharge machining (EDM) is a flexible machining process used to produce a variety of components for rigorous precision and precision. In this process, the material is removed by a series of sparks generated between the two poles (anode and cathode) in the dielectric medium. In this process, the material transfer process takes place between electrodes, which significantly affects the performance of the component. The ability of the process is to process hard materials with complex shapes. The advantage of achieving the desired surface modifications of the workpiece with negligible shear forces makes EDM an attractive choice for composite machine materials. The temperature range of the spark developed was from 8,000 to $12,000{ }^{\circ} \mathrm{C}$ due to the excitation of a pulse generator that produces rectangular pulses with an adjustable pulse on/off times, voltage level, and peak current. Various studies in recent years have focused on improving surface quality. One of the methods to improve surface quality is to add the powder to the dielectric fluid. In the powder mixed EDM (PMEDM) process, the conductive particles mixed in the dielectric fluid reduces the insulation possibility of dielectric fluid and increases the electrical discharges between the electrode and the workpiece (K. Furutani, Saneto, Takezawa, Mohri, \& H.Miyake, 2001). Besides, the spark discharges are more even and extended (Zhao, Meng, \& Wang, 2002), leading to the reduced charge density, which makes the craters becomes shallower. Consequently, the process becomes more stable and results in better surface quality. The result in(Erden \& Bilgin, 1980)showed the effect of the impurity particles in the dielectric fluid of the EDM process and reported that adding alloy powder into the solvent did improve the surface quality, the ability to remove material, tool wear reduction. Recently, researchers have focused on improving surface quality; some of the published works are mentioned as follows:

The SiC powder is studied by S.Sahu et al. (Sahu, Jadam, Datta, \& Nandi, 2018), the authors reported that material removal rate, tool wear rate, the morphology and topographical features of the machined surface including surface roughness, crack density, white layer thickness has been improved over conventional EDM .G. Talla et 
al.(Talla, Gangopadhyay, \& Biswas, 2016) studied the effects of three powders including aluminum powder (Al), graphite powder and Silicon powder ( $\mathrm{Si}$ ) in the EDM process on Inconel 625. The authors point to the effect of each type of powder to improve the surface quality and material removal rates. Graphite powder has the highest effect on material removal rate, and silicon powder has the highest effect on microhardness of surface. M. Marashi and et al.(Marashi, Sarhan, \& Hamdi, 2015) studied the effect of $\mathrm{TiO} 2$ powder in EDM on the surface properties of AISI D2 steel. As a result, the craters are shallower. The cracks are gradually reduced on the surface of the workpiece. F. Amorim et al.(Amorim, Dalcin, Soares, \& Mendes, 2017) investigated surface modification after EDM machining with the addition of molybdenum powder on AISI H13. The research results of the report showed a great influence on the recast layer, the microhardness of surface, molybdenum powder size has a great influence on the recast layer, the microhardness of surface. L.Li et al.(Li, Zhao, Li, Feng, \& Bai, 2017) reported the effect of SiC powder added to insulating oil to process Ti-6Al-4V by the EDM method. The results showed that the properties of the surface layer were significantly improved. C. Prakash et al. (Prakash, Kansal, Pabla, \& Puri, 2017) studied surface modification when processing Ti-35Nb-7Ta-5Zr $\beta$-Titanium Alloy with Si powder added in EDM. The results showed a significant improvement in surface modification, in addition to the improvement in material removal rate and electrode wear. Jabbaripour et al.(Jabbaripour, Hossein, Reza, \& Faraji, 2013) studied the influence of $\mathrm{Al}, \mathrm{Gr}, \mathrm{SiC}, \mathrm{Cr}, \mathrm{Fe}$ powders in the process of EDM to the surface roughness of the alloy TiAl. The authors had shown that the improvement of Al powder on the surface roughness compared to that of normal EDM by $32 \%$. AISI D2 die steel samples were studied by A.Al-Khazraji et al.(Al-Khazraji, Amin, \& Ali, 2016) on surface modification during EDM processing with the addition of $\mathrm{SiC}$ powder with two copper and graphite electrodes, the results showed that the thickness of The white layer and fatigue life has significantly changed compared to the EDM method, the authors also pointed out the suitability of each type electrode with added powders for surface modification. The addition of reduced graphene oxide powder to EDM steel $55 \mathrm{NiCrMoV7}$ processing was investigated by R. Świercz et al.(Świercz \& Oniszczuk-świercz, 2019) the authors reported a change in surface modification. The surface roughness and thickness of the white layer have a significant decrease compared to EDM; besides, there is an assessment of the formation of white layer thickness through the positive polarity and the negative polarity. T. D. Nguyen et al.(Nguyen, Nguyen, \& Banh, 2018) has investigated the addition of Ti powder. The authors reported a change in surface modification. The surface roughness decreased, and the microhardness of surface increased significantly compared to conventional EDM. The surface modification of Ti6Al4V has been investigated when the SiC powder is added into the dielectric fluid. It is reported by T. Öpöz et al.(Öpöz, Yaşar, Ekmekci, \& Ekmekci, 2018), the results showed that the hardness layer increased due to $\mathrm{SiC}$ penetration into the surface. Carbon nanotubes (CNTs) have been added into the dielectric fluid to process $\mathrm{Ti}-6 \mathrm{Al}-$ 4V alloy materials by the EDM method. It was reported by M. Shabgard et al.(Shabgard \& Khosrozadeh, 2017), the authors have shown that the material removal rate, electrode wear rate, surface quality (surface roughness, micro-cracks) have been significantly improved. B. Ekmekci et al.(Ekmekci, Yaşar, \& Ekmekci, 2016) studied the form of discharging when SiC powder involved affects the surface properties, the results showed the improvement of surface properties due to the participation of $\mathrm{SiC}$ powder.

There are currently very few studies on the effect of tungsten powders on surface modification of workpiece: S.Kumar and U.Batra(Kumar \& Batra, 2012) studied the effect of adding tungsten powder into the dielectric fluid on the microhardness of surface of three types of OHNS, D2, and H13 steels, resulting in the micro hardness of the surface of three types of steel are increased by more than $100 \%$, the increase in microhardness surface increases the wear resistance, which is very useful for the molds and the mechanical part, that require high abrasion resistance. Bhattacharya et 
al.(Bhattacharya, Batish, \& Kumar, 2013) investigated the effect of mixing tungsten powder in the dielectric fluid to process the copper material with a $\mathrm{W}-\mathrm{Cu}$ electrode, that gave a fine surface after work, showing specifically that: Microhardness of surface is significantly improved. S. Mohanty et al.(Tyagi, Das, \& Mandal, 2018) Ti6Al4V was investigated for surface modification during EDM machining with the participation of tungsten disulfide (WS2) powder mixed in deionized water. The results showed a significant improvement in microhardness (HV), the thickness of the recast layer (RLT), material deposition rate (MDR), and surface roughness (SR). Wear resistance is tested; the results show better than the base material.

Thus, this study aims to investigate the penetration of chemical components on the surface of SKD61 steel after being processed by the EDM method with the mixing of tungsten carbide powder into the dielectric fluid affecting the surface microstructure of workpiece SKD61 at fine finishing and semi-finishing processes. By determining the change in the content of chemical elements, these elements affect the surface microstructure.

\section{MATERIALS AND METHODS}

The total experiment plan is shown in figure 1. The following sessions describe in detail the materials and methods of the experiments.

\subsection{Materials and Equipment}

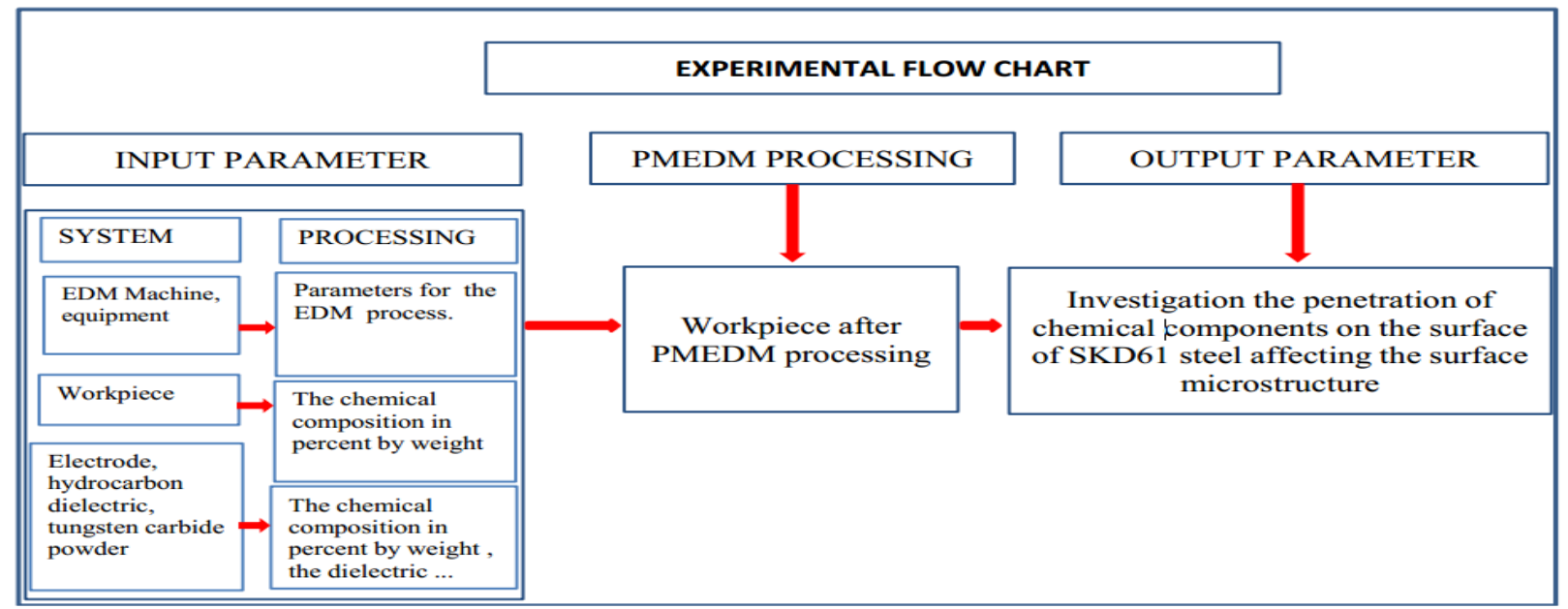

Figure 1: Experiment Plan

Steel SKD61 was used in the experiment (supplied by the Daido Corporation of Japan). Table 1 shows the chemical composition of steel SKD61. The dielectric fluid is Shell Oil EDM Fluid 2. The technical properties are shown in table 2. The tungsten carbide powder is used in this experiment by Praxair Surface Technologies with code WC-727-6. The chemical composition and the particle size in percent by weight of tungsten carbide metal powder are shown in table 3 and table 4 , respectively.

Table 1: The Chemical Composition in Weight Percentage of SKD61

\begin{tabular}{|c|c|c|c|c|c|}
\hline $\mathbf{C}$ & $\mathbf{S i}$ & $\mathbf{C r}$ & $\mathbf{M o}$ & $\mathbf{V}$ & $\mathbf{M n}$ \\
\hline$\leq 0,38 \%$ & $\leq 1,0 \%$ & $\leq 5,0 \%$ & $\leq 1,25 \%$ & $\leq 1,0 \%$ & $\leq 0,4 \%$ \\
\hline
\end{tabular}


Table 2: The Technical Properties of Shell Oil EDM Fluid 2

\begin{tabular}{|l|l|c|}
\hline \multicolumn{1}{|c|}{ Properties } & \multicolumn{1}{c|}{ Unit } & Value \\
\hline Velocity at $40^{\circ} \mathrm{C}$ & $\mathrm{cSt}$ & 2.25 \\
\hline Density at $15^{\circ} \mathrm{C}$ & $\mathrm{kg} / \mathrm{l}$ & 0.773 \\
\hline Freezing temperatures (Max) & ${ }^{0} \mathrm{C}$ & -27 \\
\hline Thermal conductivity & $\mathrm{W} / \mathrm{m}^{0} \mathrm{C}$ & 0.01 \\
\hline
\end{tabular}

Table 3: The Chemical Composition of Tungsten Carbide Powder

\begin{tabular}{|c|c|c|c|c|}
\hline C & Co & Fe & W & Other components \\
\hline $5.56 \%$ & $11.9 \%$ & $0.02 \%$ & $82.5 \%$ & $<0.01$ \\
\hline
\end{tabular}

Table 4: The Particle Size in Weight Percentage of Tungsten Carbide Powder

\begin{tabular}{|c|c|c|c|c|}
\hline $5.5 \mu \mathrm{m}$ & $11 \mu \mathrm{m}$ & $16 \mu \mathrm{m}$ & $22 \mu \mathrm{m}$ & $31 \mu \mathrm{m}$ \\
\hline $5.23 \%$ & $20.75 \%$ & $33.76 \%$ & $29.61 \%$ & $10.65 \%$ \\
\hline
\end{tabular}

\subsection{Experimental Method}

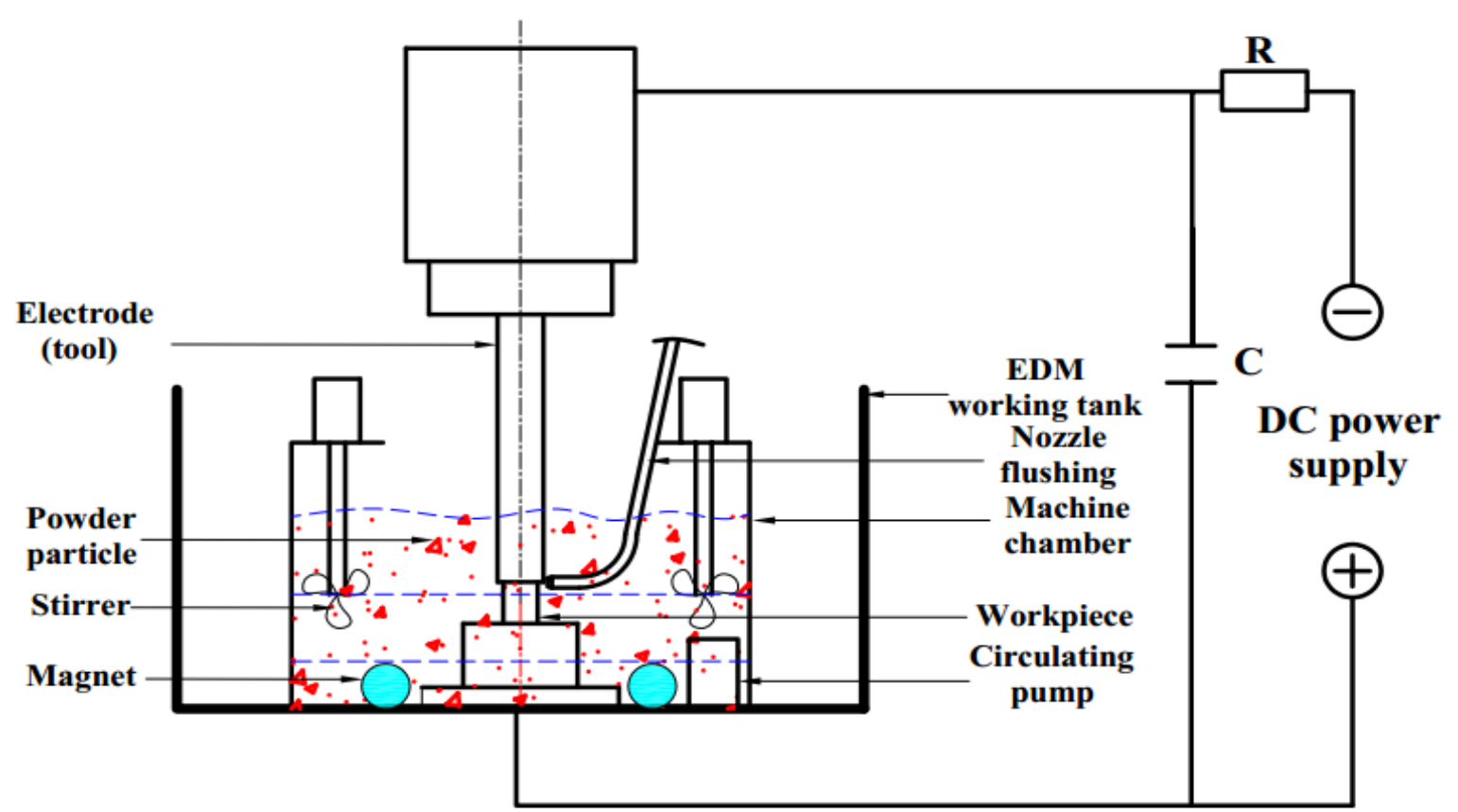

Figure 2: Setup Experimental Diagram

An electrical discharge machine from the Aristech (CNC-460 EDM), was used to remove the upper part of the SKD61 workpiece to obtain dimensions, as in Fig. 2. The copper electrode polarity was negative. In this experiment, the tungsten carbide powder was mixed into the dielectric fluid with the concentrations, as in Table 5. The parameters of the process are given in Table 5. The chemical composition and the SEM of the surface were measured by the JSM6610LAJEOL (JAPAN). 
Table 5: Experimental Conditions

\begin{tabular}{|l|c|c|c|c|c|}
\hline Condition & $\begin{array}{c}\text { Peak current } \\
\left(\mathbf{I}_{\mathbf{p}}\right)\end{array}$ & $\begin{array}{c}\text { Pulse on } \\
\left.\text { time( } \mathbf{T}_{\text {on }}\right)\end{array}$ & $\begin{array}{c}\text { Pulse off } \\
\left.\text { time( } \mathbf{T}_{\text {off }}\right)\end{array}$ & $\begin{array}{c}\text { Current-voltage } \\
(\mathbf{V})\end{array}$ & $\begin{array}{c}\text { Powder } \\
\text { Concentration } \\
\left(\mathbf{C}_{\mathbf{p}^{-}} \mathbf{g} / \mathbf{l}\right)\end{array}$ \\
\hline Detail & $1 \mathrm{~A} ; 2 \mathrm{~A}$ & $50 \mu \mathrm{s} ; 200 \mu \mathrm{s}$ & $50 \mu \mathrm{s}$ & $80-120 \mathrm{~V}$ & $20 ; 60$ \\
\hline
\end{tabular}

\section{RESULTS AND DISCUSSIONS}

In figure $3 ; 4 ; 5 ; 6:$ SEM of the surface microstructure of the sample after PMEDM machining, it is also the area for EDX scanning. The next is the graph of the energy level of the elements determined by EDX, and finally, the table of the content of elements on the surface of the workpiece. First of all, consider the change in element composition on the surface of the workpiece.

\subsection{The Chemical Composition on the Surface of the Workpiece}

In figure $3 ; 4 ; 5 ; 6$, the chemical composition has been changed as compared to the substrate of SKD61 steel, as follows: The Mn has been completely removed, the Fe content has reduced, Carbon content increases compared to the substrate layer, the Cobalt element appears in the surface workpiece of at $\mathrm{I}_{\mathrm{p}}=1 \mathrm{~A} ; \mathrm{C}_{\mathrm{p}}=20 \mathrm{~g} / \mathrm{l} ; \mathrm{T}_{\text {on }}=50 \mu \mathrm{s} ; \mathrm{T}_{\text {on }}=200 \mu \mathrm{s}$, but in the remaining investigation regimes, there was no occurrence of cobalt elemental content, the tungsten content has appeared in the surface workpiece, depending on the technological mode, the tungsten content appears different in the surface workpiece, the tungsten in surface layer can improve mechanical, physical and chemical properties of the surface.

According to figure $3 ; 4 ; 5 ; 6$, at technological modes with the powder concentration $\mathrm{C}_{\mathrm{p}}=20 \mathrm{~g} / \mathrm{l}$, the content of carbon element obtained after processing is less than $10 \%$ in the Fig. 3.a; 4.a; 5.a; 6.a. But at technological modes with the powder concentration $\mathrm{C}_{\mathrm{p}}=60 \mathrm{~g} / \mathrm{l}$, the content of carbon element obtained after processing is greater than $10 \%$ in figure $3 . \mathrm{b}$; 4.b; 5.b; 6.b. The cause of this phenomenon is that as the concentration of powder increases, leading to more carbon elements in the powder, making the process of penetration of carbon elements into the surface is more active than the low powder concentration. Besides, the EDM process has cracked the carbon from the dielectric fluid to penetrate into the surface of the workpiece.

Through the determination of the content of elements present in the surface, it is found that the tungsten content at modes with a short pulse on time penetrates into the surface is greater than that at the modes with a long pulse on time. This is evidenced by the result of determining the content of elements by the EDX method in figure $3 ; 4 ; 5 ; 6$. The phenomenon can be explained as follows:

The tungsten content at modes with a short pulse on time: Due to the appropriate combination between the peak current, the pulse on-time and pulse off time, the breaking pressure of gas bubble formed in the previous discharge period is small, causing the high concentration of the metal particles in the discharge channel formed for the next discharge period. While those particles are important in forming the bridge of the metal particles for spark discharge, such high concentration leads to an increase in the sparking distance, resulting in a more even density of spark discharge. In total, those are the main reasons for more tungsten content on the surface of the workpiece.

The tungsten content at modes with a long pulse on time: The cause of the phenomenon for those cases can be explained similarly to the above, where the inappropriate combination between the peak current, the pulse on-time and pulse off time, the breaking pressure of gas bubble formed in the previous discharge period is high, causing the low concentration of the metal particles in the discharge channel formed for the next discharge period. The resulting reduction 
in the sparking distance leads to a less even density of spark discharge and thus causes the less tungsten content on the surface of the workpiece.

\subsection{The SEM of Surface Microstructure}
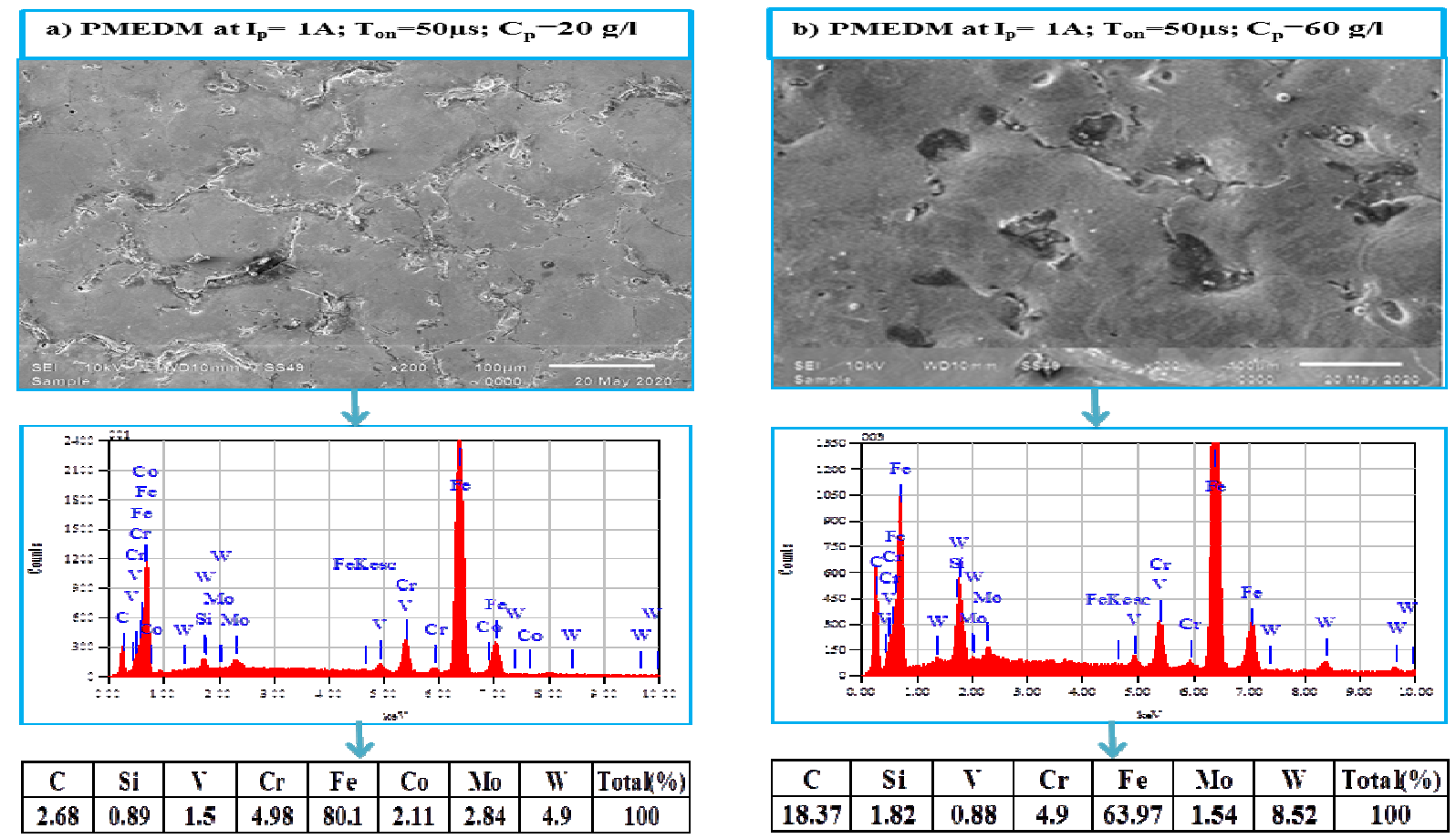

Figure 3: The SEM of Surface Microstructure and the Chemical Composition by EDX at $I_{p}=1 A$;
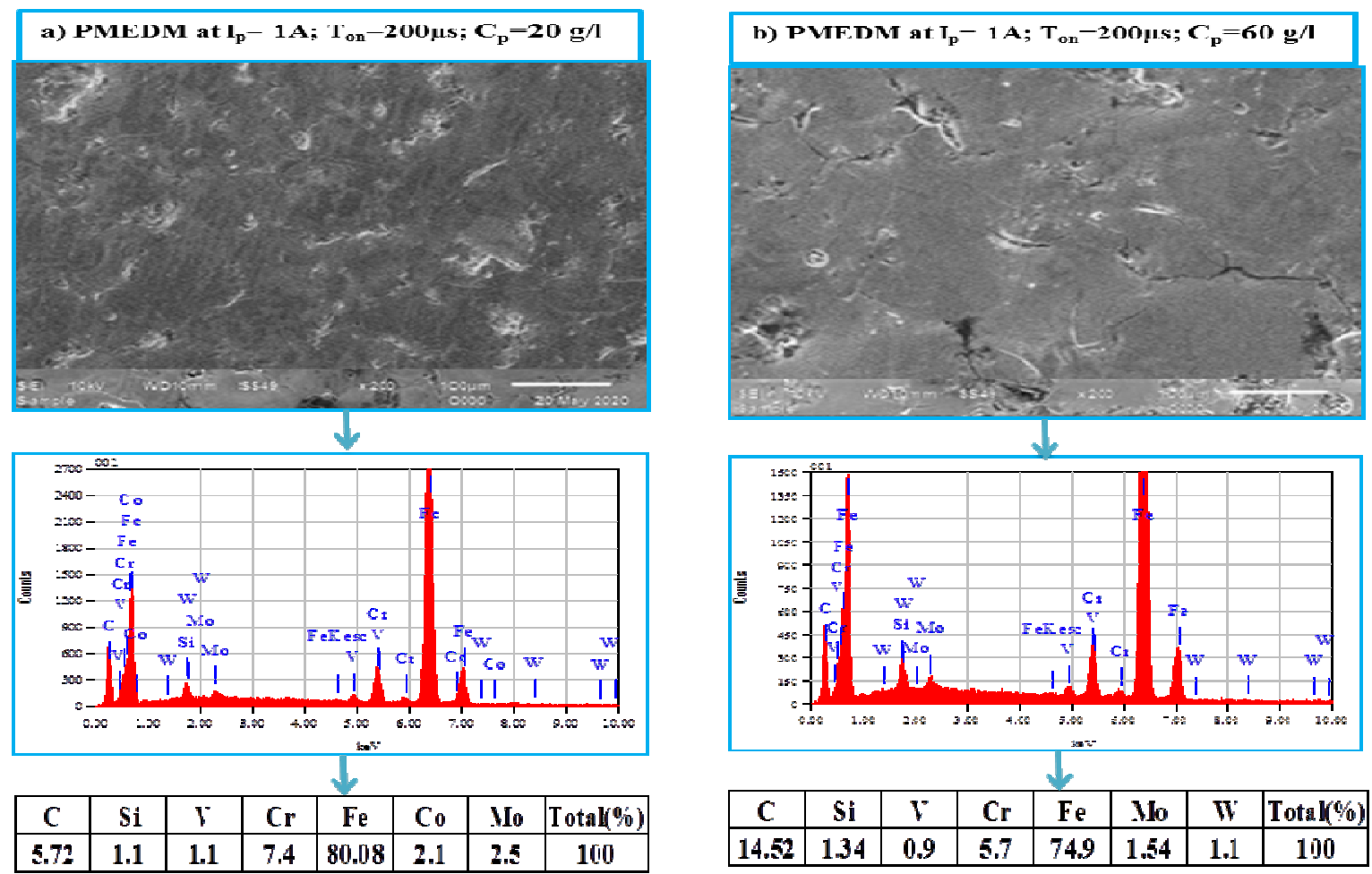

Figure 4: The SEM of Surface Microstructure and the Chemical Combosition bv EDX at In=1A: 

SKD61 Steel to the Surface Microstructure in PMEDM Process
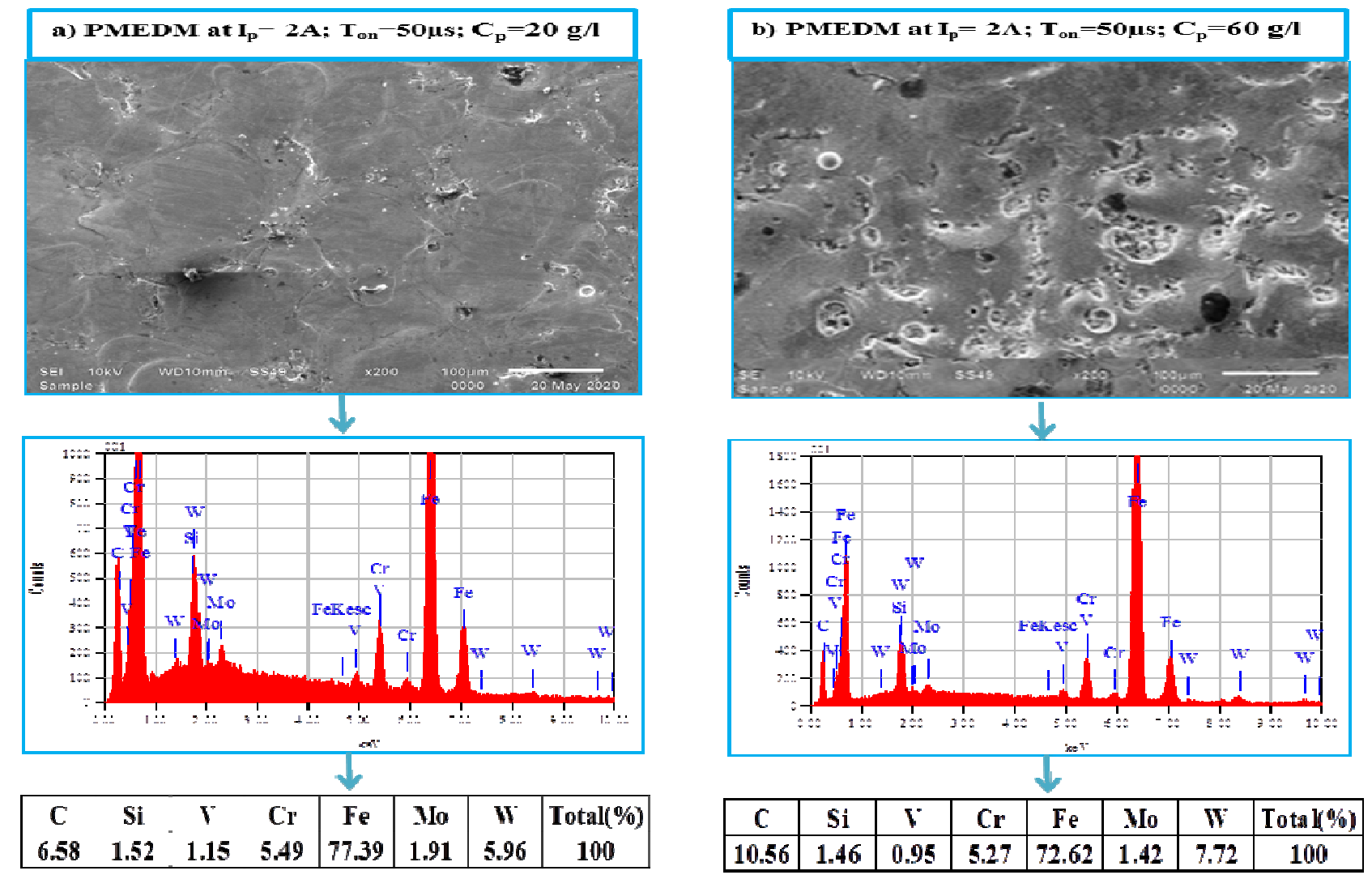

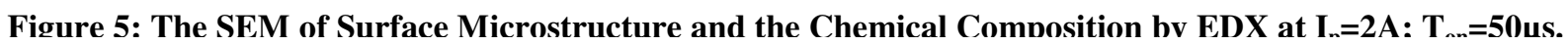
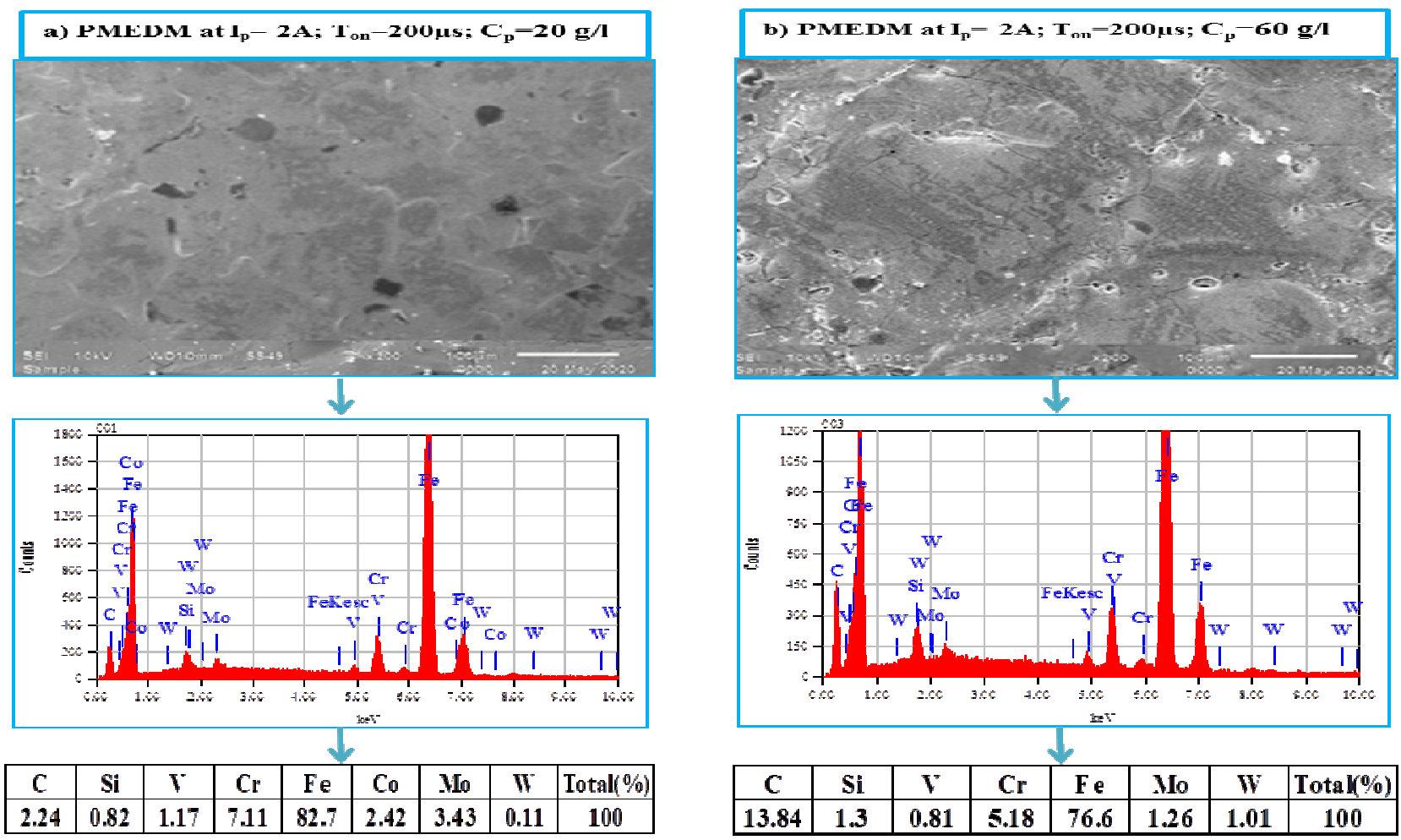

Figure 6: The SEM of Surface Microstructure and the Chemical Composition by $\mathbf{E D X}$ at $\mathrm{I}_{\mathrm{p}}=\mathbf{2 A}$; $\mathrm{T}_{\mathrm{on}}=200 \mu \mathrm{s}$. 
In figure $3 . b ; 4 . b ; 5 . b ; 6 . b$ are shown that the SEM of surface microstructure is very rough, and there are many micro-cracks on the surface of the workpiece, which are often large and long. Contrary to this, in figure 3. a; 4.a; 5.a; 6.a are shown that the SEM of surface microstructure is very smooth, and there are few micro-cracks on the surface of the workpiece, which are often small and short. Thus, it is found that at electrical technology modes, these surfaces with smooth microstructure often receive at low powder concentration $\left(C_{p}=20 \mathrm{~g} / \mathrm{l}\right)$, these surfaces with rough microstructure often receive at high powder concentration $\left(C_{p}=60 \mathrm{~g} / \mathrm{l}\right)$. The causes of these phenomena are as follows: According to section 3.1 investigating the content of elements in the surface of the workpiece, it is found that the surfaces with rough microstructure usually have a higher content of carbon and tungsten than those with smooth microstructure, especially the content of carbon element has a great influence on the surface microstructure. When these two elements penetrate into the surface more or less, the combination with the pulse on-time and pulse off time is unsuitable or suitable. If pulse on time and pulse off time is suitable, the content of carbon and tungsten elements is little, and these two reasons will create a smooth microstructure surface. If pulse on time and pulse off time is unsuitable, the content of carbon and tungsten elements is much, lead to will create a rough microstructure surface. In total, those are the main reasons for the smooth microstructure surface or the rough microstructure surface.

\section{CONCLUSIONS}

In this current study, the investigation of the content of chemical elements on the surface of SKD61 steel has been machined by the PMEDM method. The main results can be summarized as follows:

- Based on the investigation of change in the content of chemical elements on the surface, which greatly affects the surface microstructure. It finds that the main factor affecting the surface microstructure is carbon.

- The surfaces with high powder concentration $\left(\mathrm{C}_{\mathrm{p}}=60 \mathrm{~g} / \mathrm{l}\right)$ have a higher carbon content than the surfaces with low powder concentration $\left(C_{p}=20 \mathrm{~g} / \mathrm{l}\right)$ at all electrical technology modes, which were investigated in this study.

- For surfaces with a carbon content greater than $10 \%$, there are a rough surface microstructure and lots of microcrack. In contrast, for surfaces with carbon content less than $10 \%$, there are a smooth surface microstructure and less micro-crack.

\section{REFERENCES}

1. Al-Khazraji, A., Amin, S. A., \& Ali, S. M. (2016). The effect of SiC powder mixing electrical discharge machining on white layer thickness, heat flux and fatigue life of AISI D2 die steel. Engineering Science and Technology, an International Journal, 19(3), 1400-1415

2. Amorim, F. L., Dalcin, V. A., Soares, P., \& Mendes, L. A. (2017). Surface modification of tool steel by electrical discharge machining with molybdenum powder mixed in dielectric fluid. International Journal of Advanced Manufacturing Technology, 91(1-4), 341-350

3. Bhattacharya, A., Batish, A., \& Kumar, N. (2013). Surface characterization and material migration during surface modification of die steels with silicon, graphite and tungsten powder in EDM process. Journal of Mechanical Science and Technology, 27(1), 133-140

4. Dewan, P., and B. Pradhan. "Parametric Optimization of Powder EDM Process using Grey Relational Analysis and TOPSIS." International Journal of Applied Engineering Research and Development 4 (2014): 1-10. 
5. Ekmekci, B., Yaşar, H., \& Ekmekci, N. (2016). A Discharge Separation Model for Powder Mixed Electrical Discharge Machining. Journal of Manufacturing Science and Engineering, 138(8), 1-9

6. Erden, A., \& Bilgin, S. (1980). Role of impurities in electric discharge machining. Proceedings of 21 st International Machine Tool Design and Research Conference, 345-350

7. Jabbaripour, B., Hossein, M., Reza, M., \& Faraji, H. (2013). Investigating surface roughness, material removal rate and corrosion resistance in PMEDM of $\mu$-TiAl intermetallic. Journal of Manufacturing Processes, 15(1), 56-68

8. Kumar, Satish, and Ashwani Kumar Dhingra. "Multiresponse Optimization of Process Variables of Powder Mixed Electrical Discharge Machining on Inconel-600 using Taguchi Methodology."International Journal of Mechanical and Production Engineering Research and Development (IJMPERD) 8. 1 Feb 2018, 711-722

9. K. Furutani, Saneto, A., Takezawa, H., Mohri, N., \& H.Miyake. (2001). Accretion of titanium carbide by electrical discharge machining with powder suspended in working fluid. Precis. Eng, 25, 138-144

10. Kumar, S., \& Batra, U. (2012). Surface modification of die steel materials by EDM method using tungsten powder-mixed dielectric. Journal of Manufacturing Processes, 14(1), 35-40

11. Li, L., Zhao, L., Li, Z. Y., Feng, L., \& Bai, X. (2017). Surface characteristics of Ti-6Al-4V by SiC abrasive-mixed EDM with magnetic stirring. Materials and Manufacturing Processes, 32(1), 83-86

12. Marashi, H., Sarhan, A. A. D., \& Hamdi, M. (2015). Employing Ti nano-powder dielectric to enhance surface characteristics in electrical discharge machining of AISI D2 steel. Applied Surface Science, 357, 892-907

13. Nguyen, T. D., Nguyen, P. H., \& Banh, L. T. (2018). Die steel surface layer quality improvement in titanium $\mu$-powder mixed die sinking electrical discharge machining. The International Journal of Advanced Manufacturing Technology, 100, 26372651

14. Singh, Harmandeep, and Supreet Singh. "Comparison of Various Mechanical Properties of."International Journal of Mechanical and Production Engineering Research and Development (IJMPERD) 8.3, Jun 2018, 51-58

15. Öpöz, T. T., Yaşar, H., Ekmekci, N., \& Ekmekci, B. (2018). Particle migration and surface modification on Ti6Al4V in SiC powder mixed electrical discharge machining. Journal of Manufacturing Processes, 31, 744-758

16. Prakash, C., Kansal, H. K., Pabla, B. S., \& Puri, S. (2017). Experimental investigations in powder mixed electric discharge machining of Ti-35Nb-7Ta-5Zrß-titanium alloy. Materials and Manufacturing Processes, 32(3), 274-285

17. Sahu, S. K., Jadam, T., Datta, S., \& Nandi, G. (2018). Effect of using SiC powder-added dielectric media during electrodischarge machining of Inconel 718 superalloys. Journal of the Brazilian Society of Mechanical Sciences and Engineering, 40(7), 330

18. Lathif, SK Abdul, IVS Yeswanth, and M. Srinivasulu. "An Experimental Study and Parametric Optimization of Awjc on Aluminium 7075 Alloy."International Journal of Mechanical and Production Engineering Research and Development (IJMPERD) 8.3, Jun 2018, 667-678

19. Shabgard, M., \& Khosrozadeh, B. (2017). Investigation of carbon nanotube added dielectric on the surface characteristics and machining performance of Ti-6Al-4V alloy in EDM process. Journal of Manufacturing Processes, 25, 212-219

20. Świercz, R., \& Oniszczuk-świercz, D. (2019). The effects of reduced graphene oxide flakes in the dielectric on electrical discharge machining. Nanomaterials, 9(3), 1-16

21. Talla, G., Gangopadhyay, S., \& Biswas, C. K. (2016). Effect of Powder-Suspended Dielectric on the EDM Characteristics of Inconel 625. Journal of Materials Engineering and Performance, 25(2), 704-717 
22. Tyagi, R., Das, A. K., \& Mandal, A. (2018). Electrical discharge coating using WS2 and Cu powder mixture for solid lubrication and enhanced tribological performance. Tribology International, 120, 80-92

23. Zhao, W. S., Meng, Q. G., \& Wang, Z. L. (2002). The application of research on powder mixed EDM in rough machining. Journal of Materials Processing Technology, 129(1-3), 30-33 